\title{
Interplay of mesoscale physics and agent-like behaviors in the parallel evolution of aggregative multicellularity
}

Juan A. Arias Del Angel ${ }^{1,2,3,4 \dagger}$, Vidyanand Nanjundiah ${ }^{5^{*}}$, Mariana Benítez $^{1,2^{*}}$ and Stuart A. Newman ${ }^{3^{*}}$

\begin{abstract}
Myxobacteria and dictyostelids are prokaryotic and eukaryotic multicellular lineages, respectively, that after nutrient depletion aggregate and develop into structures called fruiting bodies. The developmental processes and resulting morphological outcomes resemble one another to a remarkable extent despite their independent origins, the evolutionary distance between them and the lack of traceable homology in molecular mechanisms. We hypothesize that the morphological parallelism between the two lineages arises as the consequence of the interplay within multicellular aggregates between generic processes, physical and physicochemical processes operating similarly in living and non-living matter at the mesoscale $\left(\sim 10^{-3}-10^{-1} \mathrm{~m}\right)$ and agent-like behaviors, unique to living systems and characteristic of the constituent cells, considered as autonomous entities acting according to internal rules in a shared environment. Here, we analyze the contributions of generic and agent-like determinants in myxobacteria and dictyostelid development and their roles in the generation of their common traits. Consequent to aggregation, collective cell-cell contacts mediate the emergence of liquid-like properties, making nascent multicellular masses subject to novel patterning and morphogenetic processes. In both lineages, this leads to behaviors such as streaming, rippling, and rounding-up, as seen in non-living fluids. Later the aggregates solidify, leading them to exhibit additional generic properties and motifs. Computational models suggest that the morphological phenotypes of the multicellular masses deviate from the predictions of generic physics due to the contribution of agent-like behaviors of cells such as directed migration, quiescence, and oscillatory signal transduction mediated by responses to external cues. These employ signaling mechanisms that reflect the evolutionary histories of the respective organisms. We propose that the similar developmental trajectories of myxobacteria and dictyostelids are more due to shared generic physical processes in coordination with analogous agent-type behaviors than to convergent evolution under parallel selection regimes. Insights from the biology of these aggregative forms may enable a unified understanding of developmental evolution, including that of animals and plants.
\end{abstract}

Keywords: Myxobacteria, Dictyostelids, Liquid tissues, Deformable solids, Excitable media

\footnotetext{
*Correspondence: vidyan@alumni.iisc.ac.in; mbenitez@iecologia.unam.mx; newman@nymc.edu

${ }^{\dagger} J$ Juan A. Arias Del Angel-Deceased 2019

1 Laboratorio Nacional de Ciencias de La Sostenibilidad, Instituto de Ecología, Universidad Nacional Autónoma de México, Mexico City, Mexico

${ }^{3}$ Department of Cell Biology and Anatomy, New York Medical College, Valhalla, NY 10595, USA

${ }^{5}$ Centre for Human Genetics, Electronic City (Phase I), Bengaluru 560100, India

Full list of author information is available at the end of the article
}

\section{Introduction}

The emergence of multicellular organisms exhibiting cell differentiation, spatial patterning and morphogenesis has been recognized as one of the major transitions in evolution [1]. Depending on the criteria applied (cellcell attachment, cell communication, division of cell labor, among others) multicellularity evolved on anywhere between 10 and 25 independent occasions [2,3]. The appearance of multicellular organisms enabled an

(c) The Author(s) 2020. This article is licensed under a Creative Commons Attribution 4.0 International License, which permits use, sharing, adaptation, distribution and reproduction in any medium or format, as long as you give appropriate credit to the original author(s) and the source, provide a link to the Creative Commons licence, and indicate if changes were made. The images or other third party material in this article are included in the article's Creative Commons licence, unless indicated otherwise in a credit line to the material. If material is not included in the article's Creative Commons licence and your intended use is not permitted by statutory regulation or exceeds the permitted use, you will need to obtain permission directly from the copyright holder. To view a copy of this licence, visit http://creativeco mmons.org/licenses/by/4.0/. The Creative Commons Public Domain Dedication waiver (http://creativecommons.org/publicdomain/ zero/1.0/) applies to the data made available in this article, unless otherwise stated in a credit line to the data. 
extraordinary increase in the complexity of living systems; the study of the developmental mechanisms and selective forces leading to their emergence, maintenance, and variation is an active research area (e.g., [4-6]). In broad terms, multicellular organisms can be classified either as aggregative ("coming together") or zygotic ("staying together"), according to the mechanism by which multicellularity arises $[7,8]$. In the former, multicellular organisms develop through the gathering of several individual cells potentially belonging to different genetic lineages; in the latter, all the cells in the organism are the offspring of a single cell and remain attached to each other after cell division $[9,10]$. Across eukaryote lineages, aggregative multicellularity involves amoeboid cells and leads to the formation of a fruiting body or "sorocarp" [11]. There appear to be ecological determinants (e.g., resource availability, land vs. water environment) of whether organisms are clonal or aggregative $[9,12,13]$. Furthermore, clonal lineages do not always exhibit complex development with different cell types and arrangements, and aggregative ones often do [3, 14, 15].

Dictyostelia and myxobacteria are eukaryotic and prokaryotic multicellular lineages, respectively $[16$, 17]. In these lineages, the life cycle comprises a vegetative and a developmental stage (Fig. 1). In the vegetative stage, Dictyostelia behave as solitary cells acting independently of each other, and with the possible exception of intercellular repulsion during feeding [18], only engage in cell-cell interactions during development. In contrast, Myxobacteria, often referred to as social bacteria, are believed to organize into cell consortiums through their entire life cycles, although single-cell-specific behaviors are observed in the laboratory ([19] and unpublished observations). Both lineages are commonly found in soils where they feed upon (other) bacterial species. Once nutrients have been depleted, they transit into a developmental stage characterized by a substratum-dependent cellular aggregation that culminates in the formation of multicellular structures called fruiting bodies, containing up to $10^{5}-10^{6}$ cells, where cell differentiation takes place [20]. Unless specified otherwise, in the rest of this paper we use the terms Dictyostelium, dictyostelids and Dictyostelia interchangeably, even though the observations we consider pertain mostly to Dictyostelium discoideum, the best-studied dictyostelid species.

The basis of cell differentiation in $D$. discoideum has been explained in two ways. There are pre-aggregation tendencies among amoebae, stochastic in origin, biased by the environment they experienced during the phases of growth and division, or, cell differentiation is a post-aggregation phenomenon based on intercellular interactions and diffusible morphogens (reviewed

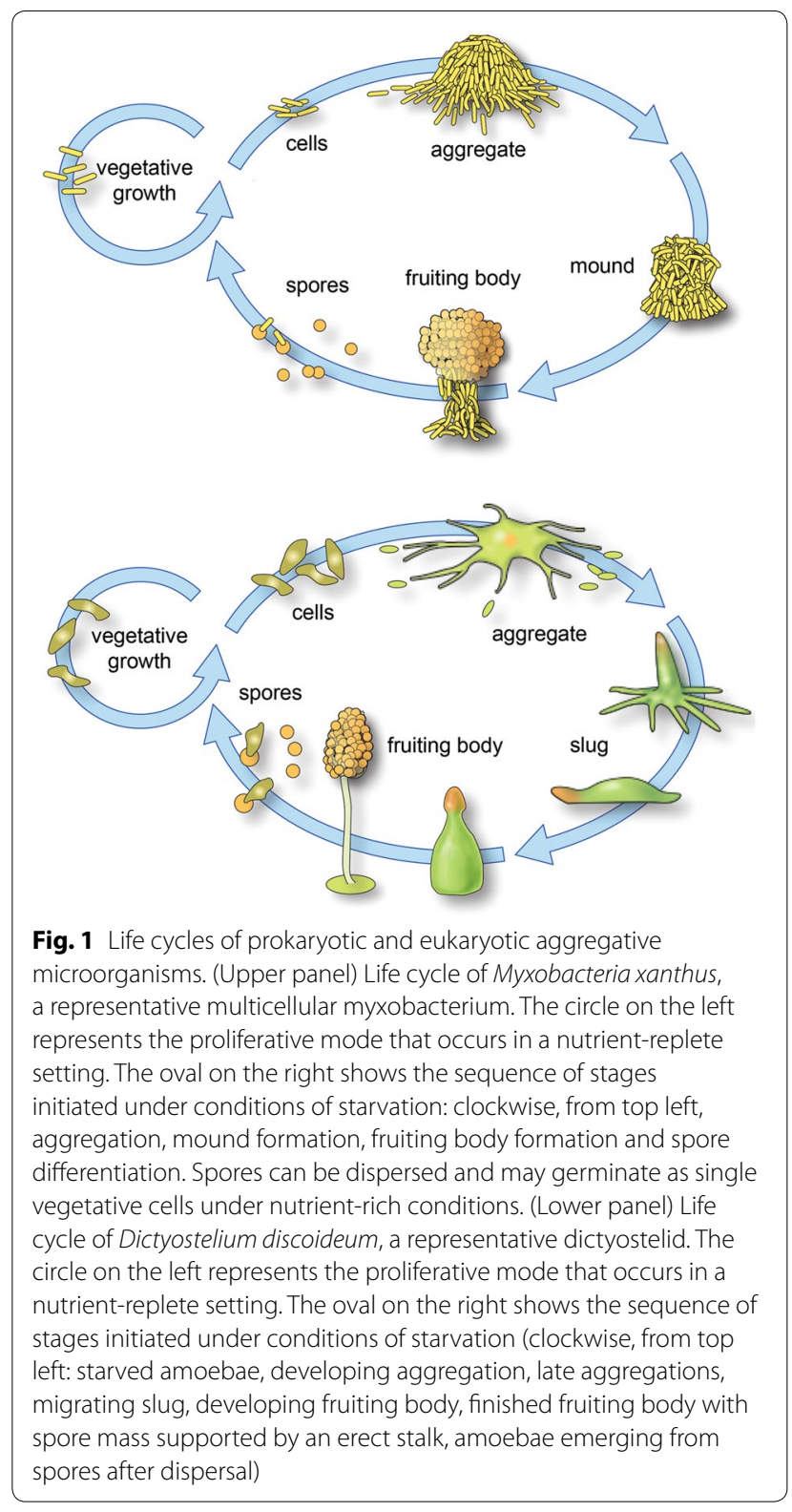

in [21]). There is experimental evidence for each of the two viewpoints [22], and it is also clear that subsequent interactions can override cell-autonomous tendencies [23].

In Myxobacteria, cells commit to at least three different cell types, peripheral rods, spores, and autolysis. In Dictyostelia, there are principally only two terminal cell types, stalk and spore cells, with several transitory cell types (different pre-stalk and pre-spore subtypes) observed over the normal course of development. Phylogenetic analyses suggest that the capacity for cellular differentiation predated the emergence of multicellular development in both lineages $[24,25]$. Theoretical 
studies show that cellular differentiation can spontaneously arise by the coupling of multistable cellular systems $[26,27]$.

The morphology of fruiting bodies in both lineages displays a similar extent of diversity ranging from simple mound-like to highly branched tree-like structures. Morphology is a species-dependent trait, though there are examples in the dictyolstelids of the fruiting body of one species mimicking the morphology of another [28]. For neither Myxobacteria nor Dictyostelia are fruiting bodies morphologies a monophyletic trait [24, 25], and thus different forms are likely to have evolved multiple times within each lineage.

The issue of convergence becomes even more remarkable when it is recognized that sorocarpic amoebae like those of Dictyostelia occur in five of the seven supergroups into which eukaryotes are divided. (Archaeplastida, the group containing red algae, green algae, and plants, appear to be the sole exception.) In another supergroup, the Alveolates, aggregative multicellularity and fruiting body formation occurs, but in ciliates, not amoebae [11,28].

Perhaps more surprising is the resemblance of developmental processes and resulting morphologies between eukaryotic sorocarpic amoebae such as Dictyostelia and the prokaryotic Myxobacteria, despite their independent origins, the evolutionary distance between them, and the lack of traceable homology in the molecular mechanisms in each group (Fig. 1). Bonner [29] suggested that the parallelisms between Myxobacteria and Dictyostelids appear as a consequence of either similar selective pressures or shared developmental constraints. But these determinants are not mutually exclusive and discrimination between them is not trivial [30]. Kaiser [31] proposed that a joint investigation of Myxobacteria and Dictyostelia could potentially lead to the identification of generalities underlying the multicellular phenotypes across both lineages.

Since Kaiser's proposal, a combination of experimental and modeling approaches has been employed to investigate the development in these two lineages [17, 32]. Such studies advanced after physicochemical processes came to be considered as key factors determining the developmental outcomes [19, 33-35]. Specifically, there is a recognition that the shaping of multicellular masses cannot be explained independently of their material properties, and that developing organisms are thus subject to physical forces and effects relevant to their composition and scale [36-39]. When applied, for example, to embryonic animal tissues, which (due to the capacity of their cellular subunits to remain cohesive while exhibiting independent motility) behave similarly in certain respects to non-living liquids, physical models predict the formation of immiscible layers, interior spaces, and, when the subunits are anisotropic, the capacity to undergo elongation $[36,40,41]$. In contrast, plant tissues, characterized by rigid cell walls, behave like deformable, mechanically and chemically active solids which (unlike liquid-state materials) can bud or branch [39].

Properties shared by cellular masses with (as the case may be) non-living liquids, solids, or semisolid materials have been termed "generic" [42], and we adopt that term here. The physical forces, effects and processes inherent to such materials enable and constrain developmental outcomes in multicellular masses, leading to the conclusion that homoplasy (the same form, independently evolved) is expected to be common, and some morphological motifs should be recurrent and predictable [37, 39]. Physical determinants, in this view, are complementary to the regulatory dynamics within cells. Indeed, physical and physicochemical processes are mobilized on the multicellular scale by genes, their products and other molecules, and are thus subject to regulation throughout evolution [39].

Based on the observation that animal life is characterized by a restricted set of basic forms and patterns, Newman and co-workers advanced the conceptual framework of "dynamical patterning modules" (DPMs) [36, 43]. DPMs are defined as sets of gene products and other molecules in conjunction with the physical and physicochemical morphogenetic and patterning processes they mobilize in the context of multicellularity. These include phenomena such as adhesion and differential adhesion, and reaction-diffusion effects. This framework emphasizes that the material nature of developing organisms makes them subject to generic physical processes and that they readily exhibit morphological motifs-layers, segments, protrusions-inherent to the respective materials. The term "module" is employed to highlight the semi-autonomous action of DPMs in determining specific spatial patterns and structures. But the DPMs also interact during development and can thus be conceptualized as a complex "pattern language" for generating organismal form. This approach is distinguished from a purely "tissue physics" framework since it also recognizes that the genetic information contained in the constituent cells makes such systems subject to evolutionary processes not applicable to non-living matter.

In contrast to the molecular subunits of non-living materials, the individual cells constituting a multicellular cluster are able to sense and respond to local cues through signaling and regulatory pathways. Because of their intracellular chemical dynamics and capacity to generate mechanical forces, cells can be understood as autonomous agents that actively modify their behavior in response to their environment, and even modify 
their environment in ways that can further affect the cell-environment interaction. These processes taking place at the cell level, include chemotaxis, which as discussed below, can continue even when the cells are already aggregated. They can translate into collective behaviors that act in parallel and coordination with, and even oppose, the generic physical processes that shape a tissue mass.

Here, we hypothesize that the morphological outcomes, and thus the parallelism between the myxobacterial and dictyostelid lineages, originated as a consequence of the interplay between generic processes acting upon the multicellular materials and agent-like behaviors, pertaining to autonomous entities acting according to internal rules in a shared environment [44], characteristic of the constituent cells. To this end, we describe the major generic and agent-like properties exhibited during the development of these lineages and attempt to analyze their contributions to the emergence of the groups' shared traits. We suggest that as a consequence of aggregation the nascent multicellular mass becomes subject to new sets of patterning and morphogenetic processes owing to the fact that cell-cell contacts or embedment in a viscous matrix mediate the emergence of a fluid-like properties. In both lineages, this leads to developmental processes, e.g., streaming, rippling, that are similar to behaviors observed in non-living fluids. We explore the idea, suggested by computational studies, that deviations of the dynamics and morphological outcomes of the multicellular mass from the generic predictions are due to the contribution of agent-like behaviors of individual cells, e.g., gradient sensing, directed migration, quiescence.

Generic effects are common causes in the different lineages. This is because whatever molecules underlie the realization of properties such as cell-cell adhesion, spatial heterogeneity via diffusion gradients, and so in in different lineages, the morphological outcomes are similar by virtue of being produced by similar physical generative processes. Agent-behaviors, in contrast, are peculiar to disparate lineages (cell locomotion, for example, has very different physical and genetic bases in prokaryotes and eukaryotes, as does entry into the quiescent state), reflecting the evolutionary histories of the respective organisms. However, these behaviors can be analogous to one another, thus contributing to convergent morphological outcomes. Further, analogous intracellular dynamical behaviors such as biochemical oscillation can be organized by generic effects such as synchronization, leading to additional shared generic modes of organization. We conclude that the similar developmental programs of Myxobacteria and Dictyostelia are plausibly due to shared generic physical processes in coordination with analogous agent-like behaviors.

\section{Generic material properties of myxobacterial and dictyostelid multicellular masses}

Even when the similarity in the mesoscopic (i.e., physics of the middle scale) properties of living and certain kinds of non-living matter is recognized, it should not be taken to imply that they are constituted in the same way. The liquid or solid nature of living tissues does not arise from the same subunit-subunit interactions that endow non-living materials with these properties. This is particularly the case with the liquid-like state of animal tissues. Instead of the thermal vibration-driven Brownian motion that causes the molecular subunits of non-living liquids to move randomly, the cells in animal tissues move actively by ATP-dependent cytoskeleton-generated forces, which in the absence of external signals is also random. Despite continually changing their neighbors, subunits of non-living liquids cohere due to the weakly attractive electronic interactions that hold them together. The cells of developing animal tissues also remain cohesive despite their translocation, but for a different reason: the homophilic attachment proteins (classical cadherins) that mediate their transient attachment extend through the cells' membranes to form stable connections between adhesive and motile functions [45]. In plant and fungal tissues, instead of the charge-based or covalent bonds of the atomic or molecular subunits of non-biological solids, the cells are cemented together by pectins and glycoproteins which are subject to unique forms of reversible remodeling $[39,46]$. Because these generic properties are dependent on evolved biological, rather than purely physical effects, the various viscoelastic and deformable solid materials that constitute living tissues have been termed "biogeneric" matter [47].

In the following, we describe some of the generic and biogeneric properties and processes of Myxobacteria and Dictyostelia multicellular masses and compare these properties to those implicated in animal development. Then, we describe the molecular components that establish and mobilize these properties in both Myxobacteria and Dictyostelia. Next, we highlight some developmental phenomena in these organisms and evaluate the extent to which these can be explained by generic-type physical behaviors, and what is left unaccounted for.

\section{Adhesion- and matrix-based cell-cell association}

Cell adhesion is the defining characteristic of multicellular organisms and the nature and strength of cell bonding is a major determinant of tissue properties [3, 27, 48]. In animals, cell-cell adhesion is mediated by membrane proteins such as cadherins that permit cells to be independently mobile and capable of moving relative to another while remaining cohesive. As noted above, the 
animal tissues from which embryos and organs develop behave formally like liquids [47].

In $D$. discoideum, cell-cell adhesion at early stages of development involves the action of several proteins including the immunoglobulin-like DdCAD-1 and the glycoproteins gp80 and gp150 whose expression and activities are tightly regulated during the different stages of development [49]. Later in development, when cells have entered into streams and cell density has increased, the cells are also embedded in cellulose-based matrices that provide the basis for adhesion in cellular conglomerates [50]. In the case of M. xanthus, persistent cohesion is correlated with the secretion of thick fibrils, composed of carbohydrates and proteins that coat the cell surface and constitute an extracellular matrix that interconnects the cells [51-53]. Chemical or genetic disruption of fibrils causes defects in agglutination and failures in social and developmental behaviors [51]. Cell-cell adhesion in Myxobacteria and Dictyostelia depend, to different degrees, on the presence of divalent cations [54, 55]. Analogously to $\mathrm{Ca}^{2+}$-dependent and $\mathrm{Ca}^{2+}$-independent mechanisms for cell-cell adhesion seen in vertebrate development, Dictyostelium development relies on the appearance of EDTA-sensitive and EDTA-insensitive contact sites [56]. At least one EDTA-insensitive adhesion protein, PsA, appears concomitantly with the formation of the multicellular slug [57].

Myxobacteria and dictyostelids also have strong associations with external substrata during their pre-culmination stages of development (Fig. 1). The closest analogy in animal systems is the interaction of cell layers in eumetazoans with internally generated planar basal laminae, which are not generally present in the earliest diverging and morphologically simplest metazoans, sponges and placozoans [58]. In both Myxobacteria and Dictyostelia cells are more loosely associated with one another as they interact with their substrata than are the cells in planar animal epithelia. In the non-animal systems, cell-substratum interactions depend on focal adhesions that indirectly (in contrast to directly in animal tissues) mediate communication between the substratum and the actin cytoskeleton, where they also provide the foundation for cellular motility $[59,60]$.

A key difference between the respective lineages is that dictyostelid cells only engage in persistent cell-cell interactions shortly after starvation, whereas extensive cell-cell adhesion and interactions take place among myxobacterial cells through their entire life cycle. While the mechanisms involved in cell-cell and cellsubstratum contact in Myxobacteria and Dictyostelia are different, in both cases the bonds between adjacent cells are weak enough to allow cells to rearrange relative to one another during aggregation and shortly after mounds are formed. Therefore, aggregating cells in these lineages behave like non-living liquids, exhibiting streaming and rippling behaviors characteristic of such materials. This contrasts with monolayered animal tissues (epithelia) which, though also having liquid-like properties in the plane, bind too strongly to their intraorganismal, basal laminae to manifest similar fluid-like behaviors at the planar interface [61].

Unlike Dictyostelia, in Myxobacteria some type of cell-cell adhesion or matrix embedment is present throughout the whole life cycle, causing cellular masses to exhibit liquid-like behaviors in both vegetative and developmental stages [19]. During predation, cells align and move concertedly into ripple-like traveling waves [62]. Once development has started, M. xanthus aggregation is largely driven by entropy minimization through reduction of the surface area on which the collective cell population contacts the substratum [63]. This is a comparable behavior to that of liquid droplets, where individual subunits or clusters move into larger droplets of larger volume but smaller contact area with the surface. In Myxobacteria, phase separation has not been implicated in sorting of cell types inside fruiting bodies. However, since spores are coated by material that increases cell cohesiveness, differential adhesion likely contributes to the spontaneous sorting out of spores from peripheral rod cells, reflecting their liquidlike properties.

It is important to distinguish the liquid-like properties of both Dictyostelia and Myxobacteria cell streams and masses from that of embryonic animal tissues. In epithelioid animal tissues the cells are directly attached to their neighbors by transmembrane cadherins which maintain strong cohesivity while permitting rearrangement. The loss of cell cohesivity, in epithelial-mesenchymal transformation, for example, can lead to abrupt changes in tissue rheology that resemble phase transitions, which have been proposed to serve as a regulatory mechanism for morphogenesis [64]. Persistent apicobasal polarization, also seen in animal systems, which allows for the formation of lumens within cell masses, and planar cell polarization which permits elongation and other reshaping of tissues by intercalation and convergent extension, a liquid crystalline-like phase transformation (reviewed in [47]). In Dictyostelia, the cells are embedded in cellulosebased matrices that enable cell rearrangement and hence the liquid-like behaviors described above [50]. However, the lack of direct engagement with the cytoskeleton in this attachment mode makes cell polarization, even when it occurs, transient and unconducive to lumen formation or stable intercalation ([65]; however, see [66]). Cells of Dictyostelia also have a more pronounced chemotactic response to extracellular signals than most animal 
embryonic cells, which contributes to their particular version of liquid-tissue properties [67] (see below).

The glycoprotein-based associations of myxobacterial cells are also too transient, and their polarity too rapidly reversible, to allow lumens to form, at least until solidification occurs during fruiting body formation (see below). However, the cells are stably elongated by default, and thus readily form liquid crystalline-like domains as in some animal tissues [19]. The rapid relative movement of the cells, though, ensures that these are only local and temporary.

To summarize, both Dictyostelia and Myxobacteria exhibit liquid-like properties, reflected in the formation of streams and rippling activity. The liquid behaviors of these aggregative forms differ from those of embryonic animal tissues. In those systems, cells are bound together by transmembrane proteins (cadherins) which keep them attached to their neighbors while they rearrange, enabling phase separation of subpopulations and layering. They also exhibit stable polarity, which enables lumen formation. The attachment modes and polarization of Dictyostelia and Myxobacteria are transient, in contrast, prohibiting the development of complex multicellular forms.

\section{Solidification}

The generic-type fluid-to-solid transitions seen during development of the aggregative species can productively be considered in relation to well-studied ones in animal embryogenesis. Animal tissues during early stages of development, as noted above, behave in important ways like non-living liquids. As development proceeds, however, some tissues undergo a transformation where cell movements become constrained and the cellular mass behaves more like a solid [45]. In these tissues, solidification may provide increased mechanical integrity, and new morphological outcomes and constructional elements (e.g., exo- and endoskeletons) arise with the physical properties of these materials. The most typical way solidification occurs is by the deposition of stiff extracellular matrices (ECM), consisting of fibrous and nonfibrous proteins such as collagen and elastin, covalently linked to, or complexed with glycosaminoglycan-type polysaccharides. These ECMs can also become mineralized, as in bone and tooth. More recently, "jamming", a liquid-to-solid transition known from colloid physics [68] has been shown to occur in liquid-state tissues as a result of increased cell-cell adhesivity [69].

In D. discoideum, cells are embedded in an ECM, which once aggregation is complete, defines the boundaries of the aggregate. Aggregation in this and related species leads to the formation of a migratory "slug" (see below), which once it reaches its final position, forms a fruiting body by building up a stalk that takes cellular material away from the surface, and in which terminal cell differentiation takes place. Membrane proteins involved in cell-cell adhesion are expressed in a cell-type-dependent fashion. Spores and stalk cells phase separate, in part, due to the resulting differential adhesion, in agreement with the expected behavior of immiscible liquids (e.g., wateroil mixtures), although other factors such as chemotaxis and differential cell motility are also involved (see below) $[23,35]$.

During fruiting body elevation, deposition of ECM is required for the stiffening and construction of the stalk [70, 71]. Solidification occurs unevenly across the cellular mass. While the movement of cells in the stalk becomes constrained because of the ECM, the remaining cells move upwards as the stalk continues to be built up following the expected dynamics of solidifying nonliving liquids. In Myxobacteria, deposition of a stiff ECM appears to be the most important factor in aggregation [19], but maturing fruiting bodies also undergo increases in cell packing density at their cores [72], as well as elaborating solid matrices formed by composites of exopolysaccharides and DNA. While the origin of the DNA is unclear, it may be released by cells after lysis (see below) [73]. Liquid-to-solid jamming phase transitions appear to also occur during fruiting body formation [74].

Here again, a phenomenon generally associated with non-living systems, transformation from a liquid to a solid phase, is found to occur in both dictyostelids and myxobacteria, albeit with different material embodiments. As with animal species where solidification underlies the ability to make morphologically analogous structures (the endoskeletons of vertebrate limbs and larval sea urchins, for example) with different ECM molecules, similar-looking arrangements in the fruiting body stages of the aggregative forms appear to depend on such changes in physical state.

\section{Differential loss of mass}

In animal morphogenesis, differential loss of mass can be achieved through programmed cell death (e.g., apoptosis, autophagy and necrosis) where, in addition to acting as cues for signaling pathways, can also induce tissue reshaping by cell elimination or mobilization of mechanical forces [75, 76]. In both Myxobacteria and Dictyostelia, it has been suggested that programed cell death may act as a mechanism for nutrient release and recycling that can be employed by the remaining cells in the population as sources of energy and cellular materials [77, 78]. However, localized developmental lysis may also be relevant in mechanical reshaping multicellular microbial masses. For example, localized cell death mobilizes mechanical forces that are instructive for the generation 
of key features during development of B. subtilis biofilms [79]. In Myxobacteria, where most of the cells in the initial population undergo developmental lysis, lysed cells may serve to strengthen the ECM by releasing DNA, as described above [73]. In Myxobacteria and Dictyostelia, peripheral rods and stalk cells, respectively, die after the stalk has been built up. In both, cell death is a consequence of nutrition deprivation.

In keeping with its eukaryotic nature, the regulation of cell death in Dictyostelium under nutrient starvation conditions, and during subsequent development, has some similarities to apoptosis in animal tissues, but there are important differences as well. Cell death is preceded by a breakdown in the mitochondrial transmembrane potential and appears to involve a homologue of the mammalian apoptosis-inducing factor (AIF), for example [80]. While chromatin becomes condensed during starvation, chromatin damage and nucleosomal 'laddering' are absent in $D$. discoideum [81, 82]. Loss of membrane asymmetry and decrease in mitochondrial potential are restricted to cells destined to die, i.e., presumptive stalk cells; there is also an increase in caspase-3 activity [82]. What is most significant for our purposes is that both of the aggregative forms employ mechanisms by which morphological outcomes are sculpted in part by cell loss, despite differences in the manner in which cell death is regulated.

\section{Agent-like behaviors in Myxobacteria and Dictyostelia}

Previous descriptions of the development of embryonic animal and plant tissues in terms of material properties of multicellular assemblages have accounted for key morphological features on the basis of generic physical processes pertaining to these materials without invoking the idea that individual cellular subunits of such materials act as autonomous agents in creating multicellular forms and patterns (see, e.g., Refs. [39, 47]). Although the constituent cells in these "generic" accounts are assumed to carry out metabolic and synthetic functions necessary to sustain life, to change their state (including polarity) in response to external signals [83], and (in the case of animal systems) locomote randomly, the materials-based perspective does not involve formal sets of rules governing cellular interactions of individually mobile cells. Similarly (as seen in the previous section), several important aspects of myxobacterial and dictyostelid development can be explained by considering them as generic materials, i.e., considering the cell streams and masses as generic liquid-like or solid-like materials.

However, attempts to computationally model aggregation of Myxobacteria and Dictyostelia cells and the resulting multicellular masses based on generic mesoscale physics have found the need to incorporate agent-like behaviors of the cells themselves into the models to capture the relevant behaviors [19, 33, 63, 84]. For biological agents such as Myxobacteria and Dictyostelia cells, these "rules" depend on intracellular dynamics of molecules and pathways.

Agent-based phenomena, which pertain to the semiautonomous activities of individual cells or cells in transient associations with each other, contrast with the collective effects governed by generic physical processes operating at the mesoscale. Unlike non-living systems, the subunits of tissues, aggregates, and presumptive aggregates are living cells that are internally complex and chemically, mechanically, and electrically active and potentially excitable. Cell dynamics can modulate the properties of biomaterials, making a liquid-like animal tissue liquid-crystalline, for example, or a solid plant tissue locally expansible. When cells act as individuals, however, alterations in their internal states can give them agent-like properties when interacting with other such agents or features of the environment. The reality of this distinction is illustrated by vertebrate neural crest migration and the formation of the lateral line sensory organs of fish, where, as relative exceptions in animal systems, cells navigate directionally through surrounding tissues in loose association with each other. Consequently agentbased modeling approaches have been deemed necessary [84-87].

In certain cases, generic properties and agent-like effects mobilize the same intracellular activities and processes. For instance, random cell movement, driven by actomyosin-based contractile and protrusive activity, is essential to the liquid-like state of animal tissues. These processes in individual amoeboid cells can also be mobilized for directional locomotion. Similarly, concerted induction of cell polarity in animals and plants can impart anisotropy to the respective tissues, changing their shapes and topology [83, 88]. In single amoeboid or bacterial cells, in contrast, polarity is essential in the sensing of chemical and substrate gradients and directed navigation. Lastly, intracellular biochemical oscillation in animal, amoebal, or bacterial cell collectives can attain synchrony, thereby causing it to behave as a "morphogenetic field" in which cell states are coordinated at long distances across the multicellular mass ([89] and references below).

As described above, multicellular systems can exhibit predictably similar morphological and patterning outcomes as a result of mobilizing generic mesoscale physics. Agent-like behaviors, however, are not generic in the same in sense, and their outcomes do not have the same kind of shared inherency, since the rules that individual cells follow in relating to other cells and their external 
environments are specific to each lineage and dependent on their respective evolutionary histories. As mentioned above, and exemplified in the phenomena of directed migration, regulated quiescence, and oscillation-based cell-cell communication, agent-like behaviors of cells as distantly related as Dictyostelia and Myxobacteria can sometimes have analogous morphological outcomes (e.g., active aggregation, formation of oriented streams; Fig. 1). This, combined with the generic effects with which they interact in the development of multicellularity, contribute to the strikingly similar morphological motifs (i.e., the erection of a stalk topped by a spore mass; Fig. 1) in these disparate systems.

\section{Directed migration}

During animal embryogenesis, the displacements of cells relative to another can be largely understood in terms of random movements analogous to the Brownian motion of the molecular subunits of non-living liquid systems [36]. In Dictyostelia and Myxobacteria, in contrast, cell trajectories deviate from the undirected motion of most animal tissues due to the action of signaling and regulatory mechanisms. These bias the direction and speed of cell movement in response to local cues in ways that may change as development progresses. We suggest that some particularities of Dictyostelia and Myxobacteria observed at the mesoscale (notwithstanding their shared liquid-like behaviors) derive from the distinct mechanisms underlying directed cell migration in these two groups.

In Dictyostelia, cell movement occurs by amoeboid motion, which is driven by cytoplasmic actomyosinbased contractile and protrusive activity just as in animal cells [90]. In contrast to the generally random cell locomotion seen in animal tissues, however, Dictyostelia exhibit both random movement and directed movement via chemotaxis, which can be thought of as a biased random walk. Amoebae seek food by chemotaxis. Aggregation is also mediated by chemotaxis, but to an aggregation pheromone (e.g., cAMP). Chemotaxis remains essential for all subsequent developmental stages [91]. It is dependent on both the physical process of diffusion of the chemoattractant (which is not a generic tissue mechanism since it is outside the cell mass) and agent-like behavior in response to the chemoattractant signaling at the cellular level. Specifically, chemotaxis is a quantifiable outcome of directional pseudopod extension [92].

In $D$. discoideum, the response to the chemoattractant cyclic AMP (cAMP) involves an oscillatory dynamics of excitation and adaptation (see below). The formation of streams with high cellular density is facilitated by the collective movement of cells coordinated by chemotaxis towards higher concentrations of cAMP. While cellular movements are most prominent at the aggregation stages, extensive cell translocation still take place at later stages of the development with chemotaxis biasing the individual movements. Oscillatory signaling persists during the translocations of cells within a slug ([93] but see [94]). Finally, in slugs and maturing fruiting bodies, chemotaxis operates jointly with differential adhesion to drive cell sorting (an authentically generic tissue process) where it also provides the basis for fruiting body elongation $[67,95,96]$.

In the case of Myxobacteria, where cells are rodshaped, the presence of protein complexes that promote motility defines a lagging and a leading pole [97]. Cells in transient contact with their neighbors move along their long axis in the direction of the leading pole, with reversals in the direction of movement being a major agent-type behavior in Myxobacteria motility. Reversals occur by switching the cellular polarity (i.e., the leading pole turns into the lagging pole and vice-versa) and net cellular displacement is influenced by the reversal frequency [98]. At the molecular level, reversals are controlled by the Frz and MglAB intracellular oscillators $[97,99]$. Directed migration is favored during development by a reduction in the frequency of reversal that allows cells to retain their direction and aggregate. This frequency reduction is stimulated by cell-cell contacts, likely involving the exchange of intercellular signals, which become more frequent as aggregation proceeds and cellular density increases [98, 100]. An additional mechanism underlying directed migration in Myxobacteria is stigmergy, by which individual cellular movement is biased by cues left behind by other cells [101]. Specifically, while moving over solid surfaces, $M$. xanthus cells deposit slime material that forms trails over which other cells travel preferentially.

In both Myxobacteria and Dictyostelia, the interplay between directed migration, an agent-like behavior, and generic material properties highlights the need to consider them together in accounting for development. In D. discoideum, cell sorting requires agent-like behaviors (directed migration) and generic properties (differential adhesion) for its completion. In Myxobacteria mesoscopic movement patterns are the result of the joint effect of the agent-like behavior of directed migration and generic liquid-like behavior enabled by transient cell-cell adhesion. In addition, the different phenomena observed along Myxobacteria life cycle also require cellular alignment that may occur spontaneously as a generic property of rod-shaped particles and cells [102, 103].

\section{Cessation of movement and quiescence}

Development in $M$. xanthus and other myxobacteria starts as a response to starvation [104]. Once it is sensed, 
ribosomes stall and the enzyme RelA increases the intracellular concentration of the tetra- and pentaphosphate alarmones (p)ppGpp which, as in most bacteria, induces the so-called Stringent Response [104-110]. As (p)ppGpp accumulates, proteases are synthesized and exported, leading to an extracellular mixture of amino acids and peptides (A-signal), where it mediates a quorum-sensing mechanism that enables a coordinated population-level response to starvation [111].While myxobacteria respond to nutrient depletion via the Stringent Response, they also require high cell density to initiate fruiting body and spore development. To effect this, in addition to conserved Stringent Response components found in non-aggregative bacteria, Myxobacteria produce CgsA, which positively regulates (p)ppGpp and is in turn positively regulated by it, and SocE, which suppresses and is suppressed by the production of (p)ppGpp $[109,112,113]$. Therefore, when A-signal rises to the concentration where it promotes aggregation [114], which in non-aggregative species would turn off the Stringent Response (since the A-signal components can serve as nutrients), the downregulation of SocE permits CgsA to keep (p)ppGpp (which is required for spore formation) elevated until development is completed.

A cleavage product of CsgA (C-signal; $[115,116])$ serves as another extracellular signal which is required for fruiting body development and sporulation. C-signal appears to be involved in cell-to-cell adhesion and coordination of cell movement during development [117] and enables multicellular aggregation and cellular differentiation $[118,119]$. In addition to A- and C-signaling, at least three other Stringent Response-associated signals (B-, Dand E-signal), mediate intercellular communication and coordination of individual cells during development, but their specific mechanisms remain unclear $[114,120]$.

In non-aggregative bacteria, the Stringent Response mediates proliferative and biosynthetic quiescence in response to nutrient depletion and other stresses. In the unicellular ancestor of myxobacteria, therefore, the genetic novelties represented by the intracellular CsgASocE circuits and the extracellular A-, B-, C-, D- and E-signals appear to have co-opted this behavior in the transition to multicellularity. By making the Stringent Response cell nonautonomous, these components and their interactions form a set of rules that enable cells of $M$. xanthus to act as agents with respect to both cessation of movement and active signaling [25]. As demonstrated in other myxobacteria such as Anaeromyxobacter dehalogenans, and Sorangium cellulosum, the Stringent Response is maintained throughout aggregation and employed in the differentiation of cells into quiescent spores and other cell types [121, 122].
Eukaryotic cells like those of Dictyostelium do not have a bacterial-type Stringent Response, but they have their own conserved sensor of nutrient depletion, the enzyme AMP-dependent protein kinase (AMPK). Among other effects, AMPK inhibits the energy utilization hub Mechanistic Target of Rapamycin Complex-1 (mTORC1) under starvation conditions [123], placing cells in an energy conserving, nonproliferative state. The enzyme functions during development of the nematode Caenorhabditis elegans, for example, to induce quiescence in germline stem cells [124]. The quiescence-inducing role of AMPK is conserved across the eukaryotes, also appearing in plants and fungi $[125,126]$.

In Dictyostelia, AMPK was found to regulate aggregate size and patterning, as well as cell fate choice and stalkspore case boundary formation in the fruiting body [127]. Deletion of the gene specifying AMPK resulted in generation of numerous small-sized aggregates (compared to wild-type cell populations) that develop asynchronously to form few fruiting bodies with small spore masses and long stalks. In contrast, when the gene is overexpressed, cells form fruiting bodies with small stalks and large spore masses [127]. Although AMPK itself functions cell autonomously, its regulation depends on interaction with other cells, mediated by soluble factors. For example, the secreted inhibitor of cell-cell adhesion Countin [128] is upregulated in AMPK null cells, and conditioned media collected from them cause wild-type cells to form smaller aggregates [127].

As with Myxobacteria, the starvation response triggers development at the expense of growth. Jaiswal and co-workers have shown that although in Dictyostelium, mTORC1 function is indeed inactivated via AMPK upon starvation, development is nonetheless initiated. These investigators have identified a class of essential starvation-upregulated, developmentally associated signaling genes and downregulated growth genes $[129,130]$. Based on the earlier work of Maurya et al. [127], downregulation of the paracrine adhesion inhibitor Countin appears to be a component of this response, suggesting as with Myxobacteria, a conserved starvation-sensing mechanism may have been recruited into a mechanism of multicellular development by one or more factors that mediate communication among agent-like cells.

\section{Oscillations as bases for both generic and agent-type behaviors}

Both Myxobacteria and Dictyostelia exhibit intracellular oscillations, which in the first case mainly involves cell polarity and direction of motion reversals, and in the second, production of chemoattractant molecules such as cAMP. Oscillations can mediate global effects if they come into synchrony in established cell masses. This 
produces developmental fields in which the constituent cells acquire a uniform state in a key modulator (e.g., the transcriptional coregulator Hes1) and therefore are poised to respond to developmental signals in a coordinated fashion. This occurs in animal systems, for example during the formation of somites, tandem blocks of tissue along the central axis of vertebrates [131], and the digits of the tetrapod limb [89]. The synchronization of oscillators can be considered a generic physical effect since the dynamical means of bringing it about, which have been mathematically characterized (see below), are limited, regardless of the underlying molecular basis of the oscillation, which can vary widely.

But oscillations of individual cells can also provide component of agent-like behavior, particularly in species that develop by aggregation. For example, they can permit cells to signal one another over distances provided they are specifically receptive to periodic stimulation. The myxobacterium $M$. xanthus exhibits a quasi-periodic reversal in the direction of motion. Reversal in the gliding cells are achieved by dynamic cell polarity that switches direction by $180^{\circ}$ [132]. As noted above, regular reversals are driven by the relocalization of polarity and motility proteins between the leading and lagging poles of the cells and allow for diverse collective modes, such as rippling in nutrient-rich media [133, 134]. Reversals also appear to be critical for complex collective behavior before and during development $[135,136]$.

Indeed, it appears that reversal frequency in $M$. xanthus drives a phase transition from two-dimensional flocking to one-dimensional streaming, therefore modulating the complex behaviors that enable the robust formation of fruiting bodies [19]. Because the reversal is coupled to intercellular signaling pathways (C-signal), this periodic switch may be synchronized between different cells and favor development [99]. A refractory period, i.e., a time lag in response to the environmental signal(s), in the molecular circuit responsible for inducing the polarity reversal, has been proposed to underlie the rippling dynamics of the bacterial sheet [97].

As in Myxobacteria, oscillations mediate collective behaviors in Dictyostelia, but they are also the basis of agent-like behaviors in these social amoebae. Initially isolated cells of $D$. discoideum aggregate by chemotactic movements in response to the release of periodic pulses of cyclic AMP, which they also amplify and relay. Specifically, when stimulated with extracellular cAMP, cells respond by synthesizing and secreting more cAMP [137, 138]. This results in non-dissipating waves of cAMP which guide aggregation of individual amoeboid cells [139]. The relay requires a refractory period, or else there would just be an explosive production of cAMP with no local gradients to guide cells into aggregates. So, a nonconstant, ultimately periodic, production of the chemoattractant by the dispersed cells is intrinsic to the patterning process.

Since the cells in this organism start out as individuals, a key question in characterizing their agent-like behavior is the relation of single cell oscillations to the global oscillations in the organizing field of cells [140]. Isolated cells are capable of oscillating [141], but it has been unclear whether such oscillations initiate the propagating waves in the "excitable medium" constituted by the field of cells [142, 143]. There are two physical possibilities. In the first, a set of oscillators (the amoebae in this case) with identical period, but randomly distributed phases come into synchrony or attain a spatiotemporal propagating mode through weak coupling, by a diffusible chemical, for example [144-146]. The second possibility is that cells only become oscillatory as a result of collective interactions, the global behavior being an emergent process. Gregor et al. [147] investigated these possibilities experimentally and via mathematical modeling, and while they confirmed that isolated cells are capable of oscillating, they concluded that the second possibility, what they term "dynamical quorum sensing", was the way that globally synchronized waves are generated in Dictyostelium.

\section{Interplay of generic properties and agent behaviors}

As we have shown, aggregative multicellular systems can change their organizational states as a result of the cell masses they form being shaped and reshaped by mesoscopic physical effects, and also by lineage-specific, "custom-built" agent-like behaviors. A schematic representing some of these factors and determinants is shown in Fig. 2. In some cases, however, developmental transformations cannot be attributed to either category of effect alone, but can only be understood as outcomes of a combination of the two acting in concert. A newly characterized example of this described by Hayakawa et al. [66], in which an ordered, liquid crystalline-like field of polarized $D$. discoideum amoebae organizes by phase separation from populations of cells of a mutant strain incapable of chemotactic signaling via cAMP. This novel patterning phenomenon, which has generictype features, occurs by "contact following locomotion", a behavior whose agent-type role in the collective motion is supported by simulations.

In the remainder of this section we will discuss two long-studied examples of such generic-agential synergy: (i) the formation and migration of multicellular slugs in dictyostelids, and (ii) formation of complex morphologies in fruiting bodies of both dictyostelids 


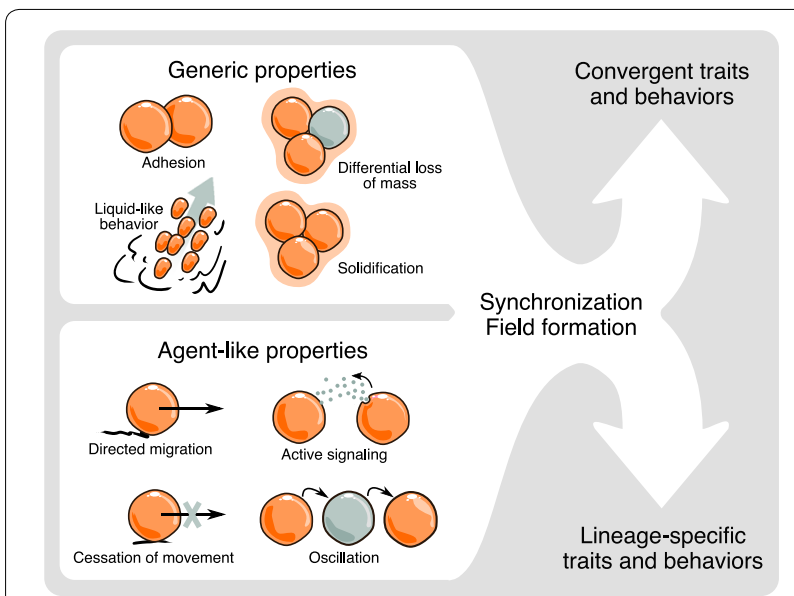

Fig. 2 Generic physical effects and agent-like behaviors that contribute to multicellular development in aggregative forms. (Left, top) A selection of generic multicellular properties and their mediators, such as adhesion and extracellular matrix embedment. (Left, bottom) A selection of agent-like effects. Some individual cell behaviors such as oscillation of biochemical state or shape or functional polarity can, when they operate in the multicellular context, mediate global generic effects, like morphogenetic fields in which cell state is coordinated over large distances. (Right) Generic processes can lead to convergent morphologies since they employ the same mesoscale physics despite genetic divergence. Agent-based processes can lead to lineage-specific behaviors and morphological motifs, but also convergent or parallel ones if they act in analogous fashions. See main text for additional examples of generic and agent effects and descriptions of their morphogenetic roles

and myxobacterial species. The second case will be seen to provide still another example of convergence of morphological phenotype resulting from the physical determinants described here.

\section{Slug formation in dictyostelium}

When starvation drives $D$. discoideum into development, the liquid-like streams that form culminate in aggregation centers. The mature aggregates, slugs, migrate over the surface in response to light and temperature gradients. Inside the slug, moving cells form smooth flow patterns similar to those of individual particles in liquids [148]. The slug is a long $(\sim 1 \mathrm{~mm})$, thin $(\sim 50 \mu \mathrm{m})$ cylindrical mass with a well-defined anterior tip that directs its movement. During aggregation and early slug formation presumptive stalk and spore cells are sorted out along the anterior-posterior axis, and their relative positions become inverted in a 'reverse fountain' manner as the fruiting body forms [84].

This process exhibits both generic mesoscopic properties but also agent-like behaviors of the constituent cells. Odell and Bonner [149], for example, used a continuum mechanics model of viscous flow in which cells moved both longitudinally, in response to an anterior-posterior cAMP gradient and transversely, in response to an unspecified gradient, to generate a rotational movement that could generate a rolling flow. Jiang et al. [150] employed a discrete lattice model in which movement was determined by chemotaxis towards a center (the tip) and energetics (cell-cell adhesion), and found that with the right balance of the two forces, a reasonably correct pattern of sorting out resulted. Umeda and Inouye [151] formulated a continuum model of a viscoelastic fluid made up of heterogeneous actively moving points (cells) that differed in various respects including their diffusive tendencies and abilities to offer resistance, and obtained, in addition to sorting out, plausible equilibrium shapes for the slug. Hogeweg, Marée, and co-workers combined agent-based and generic mechanisms-chemotaxis to cyclic AMP, differential adhesion and pressure generation-to simulate the aggregation of cells, the correct spatial distribution of cell type and their self-organization into a fruiting body [84, 152-154]. Trenchard [155] has proposed a different agent-based mechanism for sorting, one that depends on differences in speeds of movement and energetics.

\section{Fruiting body branching}

In contrast to $M$. xanthus and $D$. discoideum which exhibit branchless fruiting bodies, many of the species in both of their lineages develop into branched structures $[17,24]$. In Dictyostelia, branches develop as the product of either budding or from a secondary cellular mass generated through pinching off of the main cellular mass [24]. These mechanisms can lead to different branching patterns in different species, with in some cases arrays of secondary fruiting bodies arranged about a primary axis of stalk cells [156]. In Myxobacteria, where evidence is more limited, branches seems to develop exclusively by budding of the main cellular mass; pinching off has not been reported in this group [157]. Also, regularity in the branch distribution, as observed for whorl-developing fruiting bodies in some Dictyostelia species, has not been noted.

Cox and co-workers have carried out detailed studies on the genesis of the branching pattern in fruiting bodies of the dictyostelid Polysphondylium pallidum (now Heterostelium pallidum [158]), and their studies point to the integrated functioning of generic and agent-like processes (reviewed in [159]). P. pallidum/H. pallidum fruiting bodies are the result of secondary cellular masses being pinched off at regular intervals from the primary cell mass as it moves upward as the main stalk is formed [160]. The secondary masses turn into whorls of regularly spaced branches perpendicular to the main stalk $[161,162]$. As in D. discoideum, P. pallidum/H. pallidum 
elongation involves chemotactic movements towards a cAMP gradient, the source of which is a group of cells found at the tip of the cellular mass.

The mechanisms underlying pinching off of the secondary cellular masses remain unknown. However, since this takes place before branching, the cellular mass may still retain its liquid-like properties. Liquids may undergo pinch-off as a consequence of an imbalance of the velocities of individual subunits across the mass. If the velocities are sufficiently large, the adhesion forces will not be strong enough to permit all the fluid domains to cohere, and a (partial) pinch-off would occur. As with slug locomotion, described above, chemotaxis could induce a velocity gradient of the cells across the mass. Biased movement due to chemotaxis, along with the oscillatory intracellular dynamics, may help to explain the observed regularity in the spacing between the multiple secondary masses. This outcome, which is not trivially predicted from the generic behavior of the liquid-like primary mass, may thus depend on agent-like behavior.

The secondary cellular masses remain attached to the stalk and round up as expected for a liquid composed of homogeneously cohesive particles [161]. Branches developed from the secondary mass are regularly arranged across the plane perpendicular to the main axis. The positions of the branches are proposed to be determined by a local activation-long range inhibition effect like that described by Turing [163], although the components of this reaction-diffusion system have not been characterized [164].

The mechanism of branching itself is more problematic since it is not an expected morphology of liquid-like materials. Plant tissues, however, routinely undergo budding and branching, an effect that has been attributed to the inherent properties of their material identity as deformable solids $[39,46]$. These motifs are independently recurrent developmental outcomes in all lineages of photosynthetic eukaryotes, including the various polyphyletic algal clades and the monophyletic land plant clade, the embryophytes [46]. Both Dictyostelia and Myxobacteria undergo solidification via ECM deposition and possibly liquid-to-solid jamming in portions of the multicellular mass after aggregation has been completed (see above), and this might allow the multicellular masses to escape from the physical constraints imposed by the liquid-like behavior and acquire the properties of deformable solids for which budding and branching are easily achievable.

In addition to the transition from a liquid-like behavior to a solid one, a differential increase of volume in the direction of the future branch is required for extrusion from the main cellular mass of a secondary mass that will bud and ultimately turn into a mature branch. In plants, this is achieved by localized cell proliferation in response to gradients of hormones [165, 166]. In Myxobacteria and Dictyostelia, development proceeds with little, if any, cell division. One of two mechanisms, or a combination of them, might cause the required increment in volume: further deposition of ECM or expansion of individual cell volume. In either case, volume increase must occur in an irregular distribution over the mass, with foci of hyperplasia specifying the sites where branches will develop further.

While some myxobacterial species also have branched fruiting bodies (see, e.g., [167]), the lack of conventional chemotaxis (although see [168] for a chemotaxis-like effect in these organisms) and molecular networks for local activation-long range inhibition may account for pinch-off and regular patterning in branching, respectively, not being observed during fruiting morphogenesis in Myxobacteria. It should be noted that fruiting bodies in these species grow vertically in a series of tiers, each involving the addition of a cell monolayer. The rate of formation of new tiers is too rapid to be attributed to cell division, which suggests that cells may be recruited from lower layers $[169,170]$. This pattern of vertical growth is maintained in the face of diverse mutations and conditions, which suggests that it is an essential process in fruiting body morphogenesis [169]. Since the deposition of tiers can be slightly asymmetrical [169], branching in Myxobacteria may arise from the amplification and robust reinstitution of such asymmetries across generations.

\section{Discussion}

Motivated by the parallelisms between the two major known lineages of multicellular aggregative organisms: the prokaryotic myxobacteria and the eukaryotic dictyostelids, we have reviewed the factors determining the main developmental events in these organisms. We suggest that as a consequence of cell-cell contact during aggregation, the nascent multicellular masses of each organism acquire liquid-like properties and thereby become subject to morphogenetic processes characteristic of such materials. This allows them to be studied, and in some respects explained, in terms of physical principles at the mesoscale. As expected from the physical models, the cell aggregates can exhibit streaming, rippling, and roundingup behaviors like those observed in non-living liquids.

While the molecules that mediate liquid-type properties in the two classes of organisms are largely different, the physical processes mobilized at the multicellular scale are generic and in that sense are the "same." Furthermore, later in development cellular masses solidify and behave as deformable solids, another category of material with non-living counterparts with generic properties. For 
such materials, branching is a predictable morphological outcome.

Although the behaviors in aggregating cells resemble those exhibited by non-living liquids, mathematical and computational models have also needed to include agentbased behaviors in addition to generic ones to achieve verisimilitude [33, 84, 98, 103]. Unlike the molecular subunits of non-living liquids, the cells constituting the multicellular masses can change and adapt their behaviors in response to external cues through complex regulatory and signaling pathways. We attribute the deviations of the dynamics and morphological outcomes of the multicellular masses from generic physical predictions to the contribution of agent-like behaviors, e.g., directed migration, regulated quiescence, oscillatory signal relay, of the cells themselves. Cells of clonally developing multicellular organisms can also exhibit agent-like behaviors [171-173]. While it is difficult to quantify the relative contributions that each class of phenomena makes to the respective developmental processes, we suggest that morphogenesis of Myxobacteria and Dictyostelia is more dependent on agent-like behaviors than that of animals or plants. This is almost certainly due to their aggregative nature.

Because of the relative indifference of generic processes to molecular variation (adhesion, for example, can be mediated by many different classes of proteins and glycans), the gene products that first mediated the production of a form or structure in a species' earliest ancestors need not be the same ones that are active in its present members. Consequently, the gene products that mobilize generic effects can differ widely in different classes of organisms (e.g., animals, plants, social amoebae and bacteria), and even in sister species, due to developmental system drift [174]. In contrast, generic processes are part of the physical world, and therefore do not evolve per se, although the physical effects involved in a given lineage's developmental routines can change over phylogeny [175].

Many of the genes involved in generic processes in animal and plant lineages predated or accompanied the emergence of multicellularity. In those lineages, morphogenesis and pattern formation can be characterized in terms of the dynamical patterning modules (DPMs) that mobilize specific physical forces and physicochemical effects to produce the respective structural motifs $[39,45$, 46]. Similarly, some gene products that shape dictyostelids and myxobacteria as multicellular materials were carried over from single-celled ancestors, as were some gene products involved in agent behaviors. However, as we have described with the $M$. xanthus stringent response suppressive products CsgA and SocE, and the D. discoideum starvation-regulated paracrine factor Countin, some agent-associated genes seem to be novelties of the aggregative forms.

While DPMs are defined explicitly in reference to the multicellular scale, agents are intrinsically individual-cellular, in the cases discussed here. Another important distinction is that agents are peculiar to the biological world, in the cellular forms described here, or when they are artifacts of human activity (e.g., robots). Thus, in contrast to generic materials, which have physically predictable macroscopic properties and behaviors, cellular agents have fewer constraints on their activities. The rules they follow in developmental systems are as varied as evolved cell behaviors (e.g., motility, secretion of ions, small and macro- molecules, electrical, chemical, and mechanical excitability) and responses to microenvironmental complexity permit.

Early comparisons between Myxobacteria and Dictyostelia noted that the morphological outcomes of their respective developmental processes resembled one another to a remarkable extent despite their independent origins, the evolutionary distance between them, and the lack of gene-based homology in the relevant mechanisms in the two groups. Our attention to this phenomenon was inspired by comparative analysis of the two lineages by Bonner [29] and Kaiser [31], with a focus on common developmental mechanisms such as cell adhesion, communication and oscillations [31] and "developmental constraints" such as that incurred by increased size relative to single cells $[29,176]$. Based on the literature reviewed here, we conclude that the similar developmental trajectories and outcomes of Myxobacteria and Dictyostelia are more likely due to shared generic physical processes in coordination with analogous agent-type behaviors than to convergent evolution under parallel natural selection regimes. However, we acknowledge, in agreement with both Kaiser [31] and Bonner [176], that ecology, in the form of exploitation or construction of suitable environmental niches, is an essential factor in accounting for the establishment of these social phenotypes. Our analysis extends beyond the molecular mechanisms considered by these earlier investigators, to also include the physical nature of the multicellular masses. This approach is based on experimental and theoretical advances made in material sciences, particularly as applied to biological systems, in the intervening decades (see [48]), and progress in agent-based concepts and models [44].

Some authors have noted the tendency of aggregative multicellular organisms to exhibit a narrower and simpler morphological diversity when compared to clonal organisms such as animals and plants [10]. A common explanation of this observation is the emergence of genetic conflict arising between different cellular lineages being incorporated into the same conglomerate 
during aggregation. Despite kin selection mechanisms of "cheater" control [177], it is held that the impact of genetic conflict could still be large enough to destabilize multicellular structure and impair the evolution of further complexity. In clonal organisms, genetic conflict is thought to be avoided at every generation by genetic bottlenecks that reduce genetic diversity to those mutations emerging as consequence of DNA replication [178]. In his treatment of the evolution of Dictyostelia, Bonner [29] also suggested that selective regimens are dependent on the scale on which they operate, and that size contributes to the differences in diversity between Dictyostelia and Myxobacteria compared with plants and animals.

The physical framework addressed here provides a complement, or even an alternative, to the multilevel selection and scale-based accounts. As described above, despite the fact that animals, Dictyostelia and Myxobacteria can all be conceptualized as non-living liquids, the weaker associations between cells and surfaces in the social amoebae and bacteria lead to behaviors not observed in animals (e.g., streaming) and the stronger, cytoskeletally linked attachments in animals mediate behaviors (multilayering and lumen formation) not seen in the aggregative systems [15]. These differences are amplified by the fact that polarity (affecting, variously cell surface or shape in the different systems) is much more transient in Dictyostelia and Myxobacteria than in animals $[65,179,180]$, undermining the persistence of complex organization in the former two groups.

An important implication of the perspective we have presented here is that physics-based and agent-based approaches to understanding development are not simply alternative modeling or computational strategies, but represent realities of complex biological systems that are represented to various extents in different organismal lineages. Thus, the material nature of multicellular systems and the inherent structural motifs entailed by the relevant physics introduces a predictability to morphological evolution [45, 47]. In contrast, agent-type behaviors are more unconstrained and open-ended in their possibilities, and their evolution could have led phylogenetic lineages that embody them (e.g., vertebrates, which have the novelty of a neural crest [181]) in less predictable directions.

Comparative analyses often rely on the study of homologous characters (i.e., those sharing common ancestry) in order to disentangle phylogenetic relationships and hypothesize evolutionary scenarios. These studies, mostly conducted in the population genetics framework underlying the evolutionary Modern Synthesis, have provided important insights regarding the processes of divergence of species as the product of selective pressures, genetic drift, mutation and gene flow [182]. But (with some exceptions, see [183]) they have generally neglected the role of development and, lacking a mechanistic view of phenotypic innovation [184], are limited in the extent to which homology can be assigned between characters in disparate groups $[185,186]$.

Structures are considered homologous developmentally if they have the same form by virtue of having the same generative processes. Here we have invoked a more general sense of this concept, including in the notion of "sameness" of generic physical mechanisms in addition to genes. In this we are echoing the insights of the Soviet biologist N.I. Vavilov, who in his classic paper "The law of homologous series in variation" wrote, "[g]enetical studies of the last decades have proved even the divisibility of the minutest morphological and physiological units in systematics... and established that, although outwardly similar, they can be different genotypically" (p. 48), and that "the great majority of varietal characters, not only within the limits of single genera and families but even in distant families, are homologous from a morphological point of view" (p 82) [187].

Our broader concept of homology can potentially help resolve enigmas of biological similarity across phylogenetic distances. While some of the closest relatives of the metazoans, extant holozoans, exhibit clonal multicellularity $[188,189]$, others exhibit behaviors consistent with the idea that the animals may have arisen from unicellular ancestors by aggregation [188-190]. Knowledge of molecular and cellular determinants of material identity and agent-like behaviors in aggregative microorganisms, in concert with suitable mathematical and computational models of these causally hybrid, multiscale systems (e.g., $[98,191])$, could help forge a testable and potentially universal account of morphological evolution.

\section{Acknowledgements}

This paper is dedicated to the memory of our student and colleague, Juan Arias Del Angel. Juan framed the questions that led to this paper and wrote the first draft during a study visit to the SAN's laboratory in the summer of 2019. Juan was supported by a Consejo Nacional de Ciencia y Tecnología (CONACYT) scholarship and was a recipient of a Company of Biologists (U.K.) traveling fellowship during his work on this project. His completed Ph.D. thesis in the Programa de Doctorado en Ciencias Biomédicas Universidad Nacional Autónoma de México, based on work cited herein, was submitted after his untimely death in November. During the writing of this paper we were also saddened to learn of the passing of A. Dale Kaiser (1927-2020), which followed the recent loss of John Tyler Bonner (1920-2019). Both were major figures of biological science whose work and ideas, as well as their personal qualities, were inspirations to us. V.N. is grateful to the discussion meeting "Thirsting for theoretical biology" (ICTS/ttb2019/06) and the Biophysics Journal Club, both at the International Centre for Theoretical Sciences, for help in shaping his thoughts. Lastly, we thank Sue Seif for Fig. 1 and Luis Guillermo García Jácome for Fig. 2.

\section{Authors' contributions}

All authors contributed equally to this work. All authors read and approved the final manuscript. 


\section{Funding}

Not applicable.

\section{Availability of data and materials}

The paper contains no original data.

\section{Ethics approval and consent to participate}

Not applicable.

\section{Consent for publication}

All listed authors (with the exception of JAADA, who is deceased) have consented to publish it in its present form.

\section{Competing interests}

The authors declare no competing interests.

\section{Author details}

${ }^{1}$ Laboratorio Nacional de Ciencias de La Sostenibilidad, Instituto de Ecología, Universidad Nacional Autónoma de México, Mexico City, Mexico. ${ }^{2}$ Centro de Ciencias de La Complejidad, Universidad Nacional Autónoma de México, Mexico City, Mexico. ${ }^{3}$ Department of Cell Biology and Anatomy, New York Medical College, Valhalla, NY 10595, USA. ${ }^{4}$ Programa de Doctorado en Ciencias Biomédicas, Universidad Nacional Autónoma de México, Mexico City, Mexico.

${ }^{5}$ Centre for Human Genetics, Electronic City (Phase I), Bengaluru 560100, India.

Received: 19 June 2020 Accepted: 8 September 2020

Published online: 12 October 2020

\section{References}

1. Maynard Smith J, Szathmáry E. The major transitions in evolution. Oxford:W.H. Freeman Spektrum; 1995

2. Niklas KJ, Newman SA. The origins of multicellular organisms. Evol Dev. 2013:15:41-52.

3. Niklas KJ, Newman SA. The many roads to (and from) multicellularity. J Exp Bot. 2019;71:3247-53.

4. Niklas KJ, Newman SA, editors. Multicellularity: origins and evolution. Cambridge: The MIT Press; 2016.

5. Sebe-Pedros A, Degnan BM, Ruiz-Trillo I. The origin of Metazoa: a unicellular perspective. Nat Rev Genet. 2017;18:498-512.

6. Brunet T, King N. The origin of animal multicellularity and cell differentiation. Dev Cell. 2017;43:124-40.

7. Bonner JT. Life cycles. Princeton: Princeton University Press; 1993.

8. Tarnita CE, Taubes CH, Nowak MA. Evolutionary construction by staying together and coming together. J Theor Biol. 2013;320:10-22.

9. Bonner JT. The origins of multicellularity. Integre Biol. 1998;1:27-36.

10. Grosberg RK, Strathmann R. The evolution of multicellularity: a minor major transition? Annu Rev Ecol Evol Syst. 2007;38:621-54.

11. Brown MW, Silberman JD. The non-dictyostelid sorocarpic amoebae. In: Romeralo M, Mesquita A, Escalante R, editors. Dictyostelids evolution, genomics and cell biology. Heidelberg: Springer; 2013. p. 219-242.

12. Hamant $O, B$ hat $R$, Nanjundiah $V$, Newman $S A$. Does resource availability help determine the evolutionary route to multicellularity? Evol Dev. 2019:21:115-9.

13. Fisher RM, Shik JZ, Boomsma JJ.: The evolution of multicellular complexity: the role of relatedness and environmental constraints. bioRxiv. 2019.

14. Newman SA. Physico-genetics of morphogenesis: the hybrid nature of developmental mechanisms. In: Minelli A, Pradeu T, editors. Toward a theory of development. Oxford: Oxford University Press; 2014. p. 95-113.

15. Newman SA. Inherent forms and the evolution of evolution. J Exp Zool B Mol Dev Evol. 2019;332:331-8.

16. Romeralo M, Baldauf S, Escalante R. Dictyostelids: evolution, genomics and cell biology. Heidelberg: Springer; 2013.

17. Yang Z, Higgs PI. Myxobacteria: genomics, cellular and molecular biology. Norfolk: Caister Academic Press; 2014.

18. Keating MT, Bonner JT. Negative chemotaxis in cellular slime molds. J Bacteriol. 1977;130:144-7.

19. Thutupalli S, Sun M, Bunyak F, Palaniappan K, Shaevitz JW. Directional reversals enable Myxococcus xanthus cells to produce collective one-dimensional streams during fruiting-body formation. J R Soc Interface. 2015;12:20150049.

20. Whitworth DE. Myxobacteria: multicellularity and differentiation. Washington, DC: ASM Press; 2008

21. Nanjundiah V, Saran S. The determination of spatial pattern in Dictyostelium discoideum. J Biosci. 1992;17:353-94.

22. Kawli TS, Kaushik S. Cell fate choice and social evolution in Dictyostelium discoideum: interplay of morphogens and heterogeneities. J Biosci. 2001:26:130-3.

23. Raper K. Pseudoplasmodium formation and organization in Dictyostelium discoideum. J Elisha Mitchell Sci Soc. 1940;56:241-82.

24. Schaap P, Winckler T, Nelson M, Alvarez-Curto E, Elgie B, Hagiwara $H$, Cavender J, Milano-Curto A, Rozen DE, Dingermann T, et al. Molecular phylogeny and evolution of morphology in the social amoebas. Science. 2006;314:661-3.

25. Arias Del Angel JA, Escalante AE, Martinez-Castilla LP, Benitez M. An evo-devo perspective on multicellular development of Myxobacteria. J Exp Zool B Mol Dev Evol. 2017;328:165-78.

26. Furusawa C, Kaneko K. Origin of multicellular organisms as an inevitable consequence of dynamical systems. Anat Rec. 2002;268:327-42.

27. Mora Van Cauwelaert E, Arias Del Angel JA, Benitez M, Azpeitia EM. Development of cell differentiation in the transition to multicellularity: a dynamical modeling approach. Front Microbiol. 2015;6:603.

28. Bonner JT. The social amoebae: the biology of cellular slime molds. Princeton: Princeton University Press; 2009.

29. Bonner JT. Evolutionary strategies and developmental constraints in the cellular slime molds. Am Nat. 1982:119:530-52.

30. Olson ME. The developmental renaissance in adaptationism. Trends Ecol Evol. 2012;27:278-87.

31. Kaiser D. Control of multicellular development: Dictyostelium and Myxococcus. Annu Rev Genet. 1986;20:539-66.

32. Romeralo M, Skiba A, Gonzalez-Voyer A, Schilde C, Lawal H, Kedziora S, Cavender JC, Glockner G, Urushihara H, Schaap P. Analysis of phenotypic evolution in Dictyostelia highlights developmental plasticity as a likely consequence of colonial multicellularity. Proc Biol Sci. 2013;280:20130976.

33. Fujimori T, Nakajima A, Shimada N, Sawai S. Tissue self-organization based on collective cell migration by contact activation of locomotion and chemotaxis. Proc Natl Acad Sci USA. 2019;116:4291-6.

34. Umeda T, Inouye K. Possible role of contact following in the generation of coherent motion of Dictyostelium cells. J Theor Biol. 2002:219:301-8.

35. Bretschneider T, Othmer HG, Weijer CJ. Progress and perspectives in signal transduction, actin dynamics, and movement at the cell and tissue level: lessons from Dictyostelium. Interface Focus. 2016;6:20160047

36. Newman SA, Bhat R. Dynamical patterning modules: a "pattern language" for development and evolution of multicellular form. Int J Dev Biol. 2009;53:693-705.

37. Newman SA. Development and evolution: the physics connection. In: Love AC, editor. Conceptual change in biology: scientific and philosophical perspectives on evolution and development. Dordrecht: Springer; 2014. p. 421-440.

38. Rivera-Yoshida N, Arias Del Angel JA, Benitez M. Microbial multicellular development: mechanical forces in action. Curr Opin Genet Dev. 2018:51:37-45.

39. Benítez M, Hernández-Hernández V, Newman SA, Niklas KJ. Dynamical patterning modules, biogeneric materials, and the evolution of multicellular plants. Front Plant Sci. 2018;9:871.

40. Steinberg MS, Poole TJ. Liquid behavior of embryonic tissues. In: Bellairs R, Curtis ASG, editors. Cell behavior. Cambridge: Cambridge University Press; 1982. p. 583-607.

41. Petridou NI, Heisenberg CP. Tissue rheology in embryonic organization. EMBO J. 2019:38:e102497.

42. Newman SA, Comper WD. 'Generic' physical mechanisms of morphogenesis and pattern formation. Development. 1990;110:1-18.

43. Newman SA, Bhat R. Dynamical patterning modules: physico-genetic determinants of morphological development and evolution. Phys Biol. 2008;5:15008. 
44. Thorne BC, Bailey AM, DeSimone DW, Peirce SM. Agent-based modeling of multicell morphogenic processes during development. Birth Defects Res C Embryo Today. 2007;81:344-53.

45. Newman SA. Inherency of form and function in animal development and evolution. Front Physiol. 2019;10:702.

46. Hernández-Hernández V, Niklas KJ, Newman SA, Benítez M. Dynamical patterning modules in plant development and evolution. Int J Dev Biol. 2012;56:661-74

47. Newman SA. 'Biogeneric' developmental processes: drivers of major transitions in animal evolution. Philos Trans R Soc Lond B Biol Sci. 2016;371:20150443.

48. Forgacs $\mathrm{G}$, Newman SA. Biological physics of the developing embryo. Cambridge: Cambridge Univ. Press; 2005.

49. Coates JC, Harwood AJ. Cell-cell adhesion and signal transduction during Dictyostelium development. J Cell Sci. 2001;114:4349-58.

50. Huber RJ, O'Day DH. Extracellular matrix dynamics and functions in the social amoeba Dictyostelium: a critical review. Biochim Biophys Acta Gen Subj. 2017;1861:2971-80.

51. Arnold JW, Shimkets LJ. Cell surface properties correlated with cohesion in Myxococcusxanthus. J Bacteriol. 1988;170:5771-7.

52. Behmlander RM, Dworkin M. Integral proteins of the extracellular matrix fibrils of Myxococcus xanthus. J Bacteriol. 1994;176:6304-11.

53. Behmlander RM, Dworkin M. Biochemical and structural analyses of the extracellular matrix fibrils of Myxococcusxanthus. J Bacteriol. 1994;176:6295-303.

54. Shimkets $\sqcup$. Correlation of energy-dependent cell cohesion with social motility in Myxococcusxanthus. J Bacteriol. 1986;166:837-41.

55. Lin Z, Sriskanthadevan S, Huang H, Siu CH, Yang D. Solution structures of the adhesion molecule DdCAD-1 reveal new insights into $\mathrm{Ca}(2+)$ dependent cell-cell adhesion. Nat Struct Mol Biol. 2006;13:1016-22.

56. Siu CH. Cell-cell adhesion molecules in Dictyostelium. BioEssays. 1990;12:357-62

57. Bowers-Morrow VM, Ali SO, Williams KL. Cell adhesion during the migratory slug stage of Dictyostelium discoideum. Cell Biol Int. 2002;26:951-62.

58. Fidler AL, Vanacore RM, Chetyrkin SV, Pedchenko VK, Bhave G, Yin VP, Stothers $\mathrm{CL}$, Rose $\mathrm{KL}$, McDonald WH, Clark TA, et al. A unique covalent bond in basement membrane is a primordial innovation for tissue evolution. Proc Natl Acad Sci USA. 2014;111:331-6.

59. Faure LM, Fiche JB, Espinosa L, Ducret A, Anantharaman $V$, Luciano J, Lhospice S, Islam ST, Treguier J, Sotes M, et al. The mechanism of force transmission at bacterial focal adhesion complexes. Nature. 2016:539:530-5.

60. Fukujin F, Nakajima A, Shimada N, Sawai S. Self-organization of chemoattractant waves in Dictyostelium depends on F-actin and cellsubstrate adhesion. J R Soc Interface. 2016;13:20160233.

61. Mittenthal JE, Mazo RM. A model for shape generation by strain and cell-cell adhesion in the epithelium of an arthropod leg segment. J Theoret Biol. 1983;100:443-83.

62. Zhang H, Vaksman Z, Litwin DB, Shi P, Kaplan HB, Igoshin OA. The mechanistic basis of Myxococcusxanthus rippling behavior and its physiological role during predation. PLoS Comput Biol. 2012;8:e1002715.

63. Bahar F, Pratt-Szeliga PC, Angus S, Guo J, Welch RD. Describing Myxococcusxanthus aggregation using Ostwald ripening equations for thin liquid films. Sci Rep. 2014;4:6376.

64. Petridou NI, Grigolon S, Salbreux G, Hannezo E, Heisenberg CP. Fluidization-mediated tissue spreading by mitotic cell rounding and non-canonical Wnt signalling. Nat Cell Biol. 2019;21:169-78.

65. Manahan CL, Iglesias PA, Long Y, Devreotes PN. Chemoattractant signaling in dictyostelium discoideum. Annu Rev Cell Dev Biol. 2004;20:223-53.

66. Hayakawa M, Hiraiwa T, Wada Y, Kuwayama H, Shibata T. Polar pattern formation induced by contact following locomotion in a multicellular system. Elife. 2020;9:e53609.

67. Tan RZ, Chiam KH. Computational modeling reveals that a combination of chemotaxis and differential adhesion leads to robust cell sorting during tissue patterning. PLOS ONE. 2014;9:e109286.

68. Bi D, Zhang J, Chakraborty B, Behringer RP. Jamming by shear. Nature. 2011;480:355-8.

69. Mongera A, Rowghanian P, Gustafson HJ, Shelton E, Kealhofer DA, Carn EK, Serwane F, Lucio AA, Giammona J, Campas O. A fluid-to-solid jamming transition underlies vertebrate body axis elongation. Nature. 2018;561:401-5.

70. Palsson E. A 3-D model used to explore how cell adhesion and stiffness affect cell sorting and movement in multicellular systems. J Theor Biol. 2008;254:1-13.

71. Dickinson DJ, Nelson WJ, Weis WI. An epithelial tissue in Dictyostelium challenges the traditional origin of metazoan multicellularity. BioEssays. 2012;34:833-40.

72. Sager B, Kaiser D. Two cell-density domains within the Myxococcusxanthus fruiting body. Proc Natl Acad Sci USA. 1993;90:3690-4.

73. Hu W, Li L, Sharma S, Wang J, McHardy I, Lux R, Yang Z, He X, Gimzewski JK, Li Y, Shi W. DNA builds and strengthens the extracellular matrix in Myxococcusxanthus biofilms by interacting with exopolysaccharides. PLOS ONE. 2012;7:e51905.

74. Liu G, Patch A, Bahar F, Yllanes D, Welch RD, Marchetti MC, Thutupalli S, Shaevitz JW. Self-driven phase transitions drive Myxococcusxanthus fruiting body formation. Phys Rev Lett. 2019;122:248102.

75. Monier B, Suzanne M. The morphogenetic role of apoptosis. Curr Top Dev Biol. 2015;114:335-62.

76. Suzanne M, Steller H. Shaping organisms with apoptosis. Cell Death Differ. 2013;20:669-75.

77. Boynton TO, McMurry JL, Shimkets LJ. Characterization of Myxococcus xanthus MazF and implications for a new point of regulation. Mol Microbiol. 2013;87:1267-76.

78. Mesquita A, Cardenal-Munoz E, Dominguez E, Munoz-Braceras S, Nunez-Corcuera B, Phillips BA, Tabara LC, Xiong Q, Coria R, Eichinger $L$, et al. Autophagy in dictyostelium: mechanisms, regulation and disease in a simple biomedical model. Autophagy. 2017;13:24-40.

79. Asally M, Kittisopikul M, Rue P, Du Y, Hu Z, Cagatay T, Robinson AB, Lu H, Garcia-Ojalvo J, Suel GM. Localized cell death focuses mechanical forces during 3D patterning in a biofilm. Proc Natl Acad Sci USA. 2012;109:18891-6.

80. Arnoult D, Tatischeff I, Estaquier J, Girard M, Sureau F, Tissier JP, Grodet A, Dellinger M, Traincard F, Kahn A, et al. On the evolutionary conservation of the cell death pathway: mitochondrial release of an apoptosis-inducing factor during Dictyostelium discoideum cell death. Mol Biol Cell. 2001;12:3016-30.

81. Cornillon S, Foa C, Davoust J, Buonavista N, Gross JD, Golstein P. Programmed cell death in Dictyostelium. J Cell Sci. 1994;107(Pt 10):2691-704.

82. Kawli T, Venkatesh BR, Kennady PK, Pande G, Nanjundiah V. Correlates of developmental cell death in Dictyostelium discoideum. Differentiation. 2002;70(6):272-81.

83. Niklas KJ, Wayne R, Benitez M, Newman SA. Polarity, planes of cell division, and the evolution of plant multicellularity. Protoplasma. 2019;256:585-99.

84. Maree AF, Hogeweg P. How amoeboids self-organize into a fruiting body: multicellular coordination in Dictyostelium discoideum. Proc Natl Acad Sci USA. 2001;98:3879-83.

85. Giniunaite R, Baker RE, Kulesa PM, Maini PK. Modelling collective cell migration: neural crest as a model paradigm. J Math Biol. 2020;80:481-504.

86. Colombi A, Scianna M, Preziosi L. Collective migration and patterning during early development of zebrafish posterior lateral line. Philos Trans R Soc Lond B Biol Sci. 2020;375:20190385.

87. Dalle Nogare D, Chitnis AB. NetLogo agent-based models as tools for understanding the self-organization of cell fate, morphogenesis and collective migration of the zebrafish posterior Lateral Line primordium. Semin Cell Dev Biol. 2020;100:186-98.

88. Nance J. Getting to know your neighbor: cell polarization in early embryos. J Cell Biol. 2014;206:823-32.

89. Bhat R, Glimm T, Linde-Medina M, Cui C, Newman SA. Synchronization of Hes1 oscillations coordinates and refines condensation formation and patterning of the avian limb skeleton. Mech Dev. 2019;156:41-544.

90. Fukui Y. Mechanistics of amoeboid locomotion: signal to forces. Cell Biol Int. 2002;26:933-44.

91. Du Q, Kawabe Y, Schilde C, Chen ZH, Schaap P. The evolution of aggregative multicellularity and cell-cell communication in the dictyostelia. J Mol Biol. 2015;427:3722-33. 
92. Chopra A, Nanjundiah V. The precision with which single cells of Dictyostelium discoideum can locate a source of cyclic AMP. Chaos Solitons Fractals. 2013;50:3-12.

93. Singer G, Araki T, Weijer CJ. Oscillatory cAMP cell-cell signalling persists during multicellular Dictyostelium development. Commun Biol. 2019;2:139.

94. Hashimura H, Morimoto YV, Yasui M, Ueda M. Collective cell migration of Dictyostelium without CAMP oscillations at multicellular stages. Commun Biol. 2019;2:34.

95. Matsukuma S, Durston AJ. Chemotactic cell sorting in Dictyostelium discoideum. J Embryol Exp Morphol. 1979;50:243-51.

96. Schaap P. Evolution of developmental cyclic adenosine monophosphate signaling in the Dictyostelia from an amoebozoan stress response. Dev Growth Differ. 2011;53:452-62.

97. Guzzo M, Murray SM, Martineau E, Lhospice S, Baronian G, My L, Zhang Y, Espinosa L, Vincentelli R, Bratton BP, et al. A gated relaxation oscillator mediated by FrzX controls morphogenetic movements in Myxococcus xanthus. Nat Microbiol. 2018;3:948-59.

98. Cotter CR, Schuttler HB, Igoshin OA, Shimkets LJ. Data-driven modeling reveals cell behaviors controlling self-organization during Myxococcusxanthus development. Proc Natl Acad Sci USA. 2017;114:E4592-E46014601.

99. Igoshin OA, Goldbeter A, Kaiser D, Oster G. A biochemical oscillator explains several aspects of Myxococcus xanthus behavior during development. Proc Natl Acad Sci USA. 2004;101:15760-5.

100. Zhang Z, Igoshin OA, Cotter CR, Shimkets LJ. Agent-based modeling reveals possible mechanisms for observed aggregation cell behaviors. Biophys J. 2018;115:2499-511.

101. Gloag ES, Turnbull L, Javed MA, Wang H, Gee ML, Wade SA, Whitchurch CB. Stigmergy co-ordinates multicellular collective behaviours during Myxococcusxanthus surface migration. Sci Rep. 2016;6:26005.

102. Volfson D, Cookson S, Hasty J, Tsimring LS. Biomechanical ordering of dense cell populations. Proc Natl Acad Sci USA. 2008;105:15346-51.

103. Janulevicius $A$, van Loosdrecht M, Picioreanu C. Short-range guiding can result in the formation of circular aggregates in myxobacteria populations. PLoS Comput Biol. 2015;11:e1004213.

104. Dworkin M. Myxobacteria. eLS. 2007:a0020391.

105. Manoil C, Kaiser D. Guanosine pentaphosphate and guanosine tetraphosphate accumulation and induction of Myxococcusxanthus fruiting body development. J Bacteriol. 1980;141:305-15.

106. Manoil C, Kaiser D. Accumulation of guanosine tetraphosphate and guanosine pentaphosphate in Myxococcusxanthus during starvation and myxospore formation. J Bacteriol. 1980;141:297-304.

107. Shimkets LJ. Intercellular signaling during fruiting-body development of Myxococcusxanthus. Annu Rev Microbiol. 1999;53:525-49.

108. Chatterji D, Ojha AK. Revisiting the stringent response, ppGpp and starvation signaling. Curr Opin Microbiol. 2001:4:160-5.

109. Boutte CC, Crosson S. Bacterial lifestyle shapes stringent response activation. Trends Microbiol. 2013;21:174-80.

110. Cabello FC, Godfrey HP, Bugrysheva JV, Newman SA. Sleeper cells: the stringent response and persistence in the Borreliella (Borrelia) burgdorferi enzootic cycle. Environ Microbiol. 2017;19:3846-62.

111. Kuspa A, Plamann L, Kaiser D. A-signalling and the cell density requirement for Myxococcus xanthus development. J Bacteriol. 1992;174:7360-9.

112. Crawford EW Jr, Shimkets $\sqcup$. The Myxococcusxanthus socE and csgA genes are regulated by the stringent response. Mol Microbiol. 2000;37:788-99.

113. Crawford EW Jr, Shimkets $\sqcup$. The stringent response in Myxococcusxanthus is regulated by SocE and the CsgA C-signaling protein. Genes Dev. 2000;14:483-92.

114. Bretl DJ, Kirby JR. Molecular mechanisms of signaling in Myxococcusxanthus development. J Mol Biol. 2016;428:3805-30.

115. Gronewold TM, Kaiser D. Act operon control of developmental gene expression in Myxococcusxanthus. J Bacteriol. 2002;184:1172-9.

116. Giglio KM, Zhu C, Klunder C, Kummer S, Garza AG. The enhancer binding protein Nla6 regulates developmental genes that are important for Myxococcusxanthus sporulation. J Bacteriol. 2015;197:1276-87.

117. Sogaard-Andersen L, Overgaard M, Lobedanz S, Ellehauge E, Jelsbak $L$, Rasmussen AA. Coupling gene expression and multicellular morphogenesis during fruiting body formation in Myxococcusxanthus. Mol Microbiol. 2003;48:1-8.

118. Julien B, Kaiser AD, Garza A. Spatial control of cell differentiation in Myxococcusxanthus. Proc Natl Acad Sci USA. 2000;97:9098-103.

119. Holmes $A B$, Kalvala $S$, Whitworth DE. Spatial simulations of myxobacterial development. PLoS Comput Biol. 2010;6:e1000686.

120. Kaiser D. Signaling in myxobacteria. Annu Rev Microbiol. 2004;58:75-98

121. Huntley S, Wuichet K, Sogaard-Andersen L. Genome evolution and content in the myxobacteria. In: Yang Z, Higgs PI, editors. Myxobacteria: genomics, cellular and molecular biology. Norfolk: Caister Academic Press; 2014. p. 30-50.

122. Knauber T, Doss SD, Gerth K, Perlova O, Muller R, Treuner-Lange A. Mutation in the rel gene of Sorangium cellulosum affects morphological and physiological differentiation. Mol Microbiol. 2008;69:254-66.

123. Hardie DG. AMPK-sensing energy while talking to other signaling pathways. Cell Metab. 2014;20:939-52.

124. Kadekar P, Roy R. AMPK regulates germline stem cell quiescence and integrity through an endogenous small RNA pathway. PLOS Biol. 2019;17:e3000309.

125. Guerinier T, Millan L, Crozet P, Oury C, Rey F, Valot B, Mathieu C, Vidal J, Hodges M, Thomas M, Glab N. Phosphorylation of p27(KIP1) homologs KRP6 and 7 by SNF1-related protein kinase-1 links plant energy homeostasis and cell proliferation. Plant J. 2013;75:515-25.

126. Zhang N, Cao L. Starvation signals in yeast are integrated to coordinate metabolic reprogramming and stress response to ensure longevity. Curr Genet. 2017;63:839-43.

127. Maurya R, Kumar R, Saran S. Dictyostelium AMPKalpha regulates aggregate size and cell-type patterning. Open Biol. 2017;7:170055.

128. Jang W, Gomer $\mathrm{RH}$. Combining experiments and modelling to understand size regulation in Dictyostelium discoideum. J R Soc Interface. 2008:5(Suppl 1):S49-58.

129. Jaiswal P, Kimmel AR. mTORC1/AMPK responses define a core gene set for developmental cell fate switching. BMC Biol. 2019;17:58.

130. Jaiswal P, Majithia AR, Rosel D, Liao XH, Khurana T, Kimmel AR. Integrated actions of mTOR complexes 1 and 2 for growth and development of Dictyostelium. Int J Dev Biol. 2019;63:521-7.

131. Hubaud A, Pourquie O. Signalling dynamics in vertebrate segmentation. Nat Rev Mol Cell Biol. 2014;15:709-21.

132. Zusman DR, Scott AE, Yang Z, Kirby JR. Chemosensory pathways, motility and development in Myxococcusxanthus. Nat Rev Microbiol. 2007;5:862-72.

133. Shimkets $\sqcup$, Kaiser D. Induction of coordinated movement of Myxococcusxanthus cells. J Bacteriol. 1982;152:451-61.

134. Mauriello EM, Mignot T, Yang Z, Zusman DR. Gliding motility revisited: how do the myxobacteria move without flagella? Microbiol Mol Biol Rev. 2010;74:229-49.

135. Blackhart BD, Zusman DR. "Frizzy" genes of Myxococcusxanthus are involved in control of frequency of reversal of gliding motility. Proc Natl Acad Sci USA. 1985:82:8767-70.

136. Wu Y, Kaiser AD, Jiang Y, Alber MS. Periodic reversal of direction allows Myxobacteria to swarm. Proc Natl Acad Sci USA. 2009;106:1222-7.

137. Roos W, Nanjundiah V, Malchow D, Gerisch G (1975) Amplification of cyclic-AMP signals in aggregating cells of. FEBS Letters 53(2):139-142

138. Shaffer BM (1975) Secretion of cyclic AMP induced by cyclic AMP in the cellular slime mould Dictyostelium discoideum. Nature 255(5509):549-552

139. Tomchik KJ, Devreotes PN. Adenosine 3', '5'-monophosphate waves in Dictyostelium discoideum: a demonstration by isotope dilutionfluorography. Science. 1981;212:443-6.

140. Nanjundiah V, Wurster B. Is there a cyclic-AMP-independent oscillator in Dictyostelium discoideum? In: Goldbeter A, editor. Cell to cell signalling from experiments to theoretical models. Cambridge: Academic Press; 1989. p. 489-502.

141. Satoh H, Ueda T, Kobatake Y. Oscillations in cell shape and size during locomotion and in contractile activities of Physarum polycephalum, Dictyostelium discoideum, Amoeba proteus and macrophages. Exp Cell Res. 1985;156:79-90.

142. Cohen $\mathrm{MH}$, Robertson A. Wave propagation in the early stages of aggregation of cellular slime molds. J Theor Biol. 1971;31:101-18.

143. Durston AJ. Dictyostelium discoideum aggregation fields as excitable media. J Theor Biol. 1973:42:483-504. 
144. Kuramoto Y. Chemical oscillations, waves, and turbulence. Berlin: Springer; 1984.

145. Strogatz SH. Sync: the emerging science of spontaneous order. 1st ed. New York: Theia; 2003

146. Garcia-Ojalvo J, Elowitz MB, Strogatz SH. Modeling a synthetic multicellular clock: repressilators coupled by quorum sensing. Proc Natl Acad Sci USA. 2004:101:10955-60.

147. Gregor T, Fujimoto K, Masaki N, Sawai S. The onset of collective behavior in social amoebae. Science. 2010;328:1021-5.

148. Vasiev B, Weijer CJ. Modelling of Dictyostelium discoideum slug migration. J Theor Biol. 2003;223:347-59.

149. Odell GM, Bonner JT. How the Dictyostelium discoideum grex crawls. Philos Trans R Soc Lond B. 1986:312:487-525.

150. Jiang Y, Levine H, Glazier J. Possible cooperation of differential adhesion and chemotaxis in mound formation of Dictyostelium. Biophys J. 1998;75:2615-25

151. Umeda T, Inouye K. Cell sorting by differential cell motility: a model for pattern formation in Dictyostelium. J Theor Biol. 2004:226:215-24.

152. Savill NJ, Hogeweg P. Modelling morphogenesis: from single cells to crawling slugs. J Theor Biol. 1997;184:229-35.

153. Marée AFM. From pattern formation to morphogenesis. multicellular coordination in Dictyostelium discoideum. University of Utrecht. 2000

154. Marée AFM, Hogeweg P, Savill NJ. Dictyostelium discoidum as simulated by Mareé, Hogeweg and Savill. YouTube; 2013.

155. Trenchard H. Cell pelotons: a model of early evolutionary cell sorting, with application to slime mold Dictyostelium discoideum. J Theor Biol. 2019:469:75-95

156. Gregg K, Carrin I, Cox EC. Positional information and whorl morphogenesis in Polysphondylium. Dev Biol. 1996;180:511-8.

157. Qualls GT, Stephens K, White D. Morphogenetic movements and multicellular development in the fruiting Myxobacterium, Stigmatella aurantiaca. Dev Biol. 1978;66:270-4.

158. Sheikh S, Thulin M, Cavender JC, Escalante R, Kawakami SI, Lado C Landolt JC, Nanjundiah V, Queller DC, Strassmann JE, et al. A new classification of the dictyostelids. Protist. 2018;169:1-28.

159. Bonner JT, Cox EC. Pattern formation in dictyostelids. Semin Dev Biol. 1995;6:359-68.

160. Byrne G, Cox EC. Genesis of a spatial pattern in the cellular slime mold Polysphondylium pallidum. Proc Natl Acad Sci USA. 1987;84:4140-4.

161. McNally JG, Cox EC. Geometry and spatial patterns in Polysphondylium pallidum. Dev Genet. 1988;9:663-72.

162. McNally JG, Byrne G, Cox EC. Branching in Polysphondylium whorls: two-dimensional patterning in a three-dimensional system. Dev Biol. 1987;119:302-4.

163. Turing AM. The chemical basis of morphogenesis. Philos Trans R Soc Lond B. 1952;237:37-72.

164. Cox EC, Spiegel FW, Byrne G, McNally JW, Eisenbud L. Spatial patterns in the fruiting bodies of the cellular slime mold Polysphondylium pallidum. Differentiation. 1988;38:73-81.

165. Benkova E, Bielach A. Lateral root organogenesis - from cell to organ. Curr Opin Plant Biol. 2010;13:677-83.

166. Vermeer JE, Geldner N. Lateral root initiation in Arabidopsisthaliana: a force awakens. F1000Prime Rep. 2015:7:32

167. Zhang L, Wang H, Fang X, Stackebrandt E, Ding Y. Improved methods of isolation and purification of myxobacteria and development of fruiting body formation of two strains. J Microbiol Methods. 2003;54:21-7.

168. Taylor RG, Welch RD. Chemotaxis as an emergent property of a swarm. J Bacteriol. 2008;190:6811-6.

169. Curtis PD, Taylor RG, Welch RD, Shimkets LJ. Spatial organization of Myxococcus xanthus during fruiting body formation. J Bacteriol. 2007;189:9126-30.

170. Copenhagen K, Alert R, Wingreen NS, Shaevitz JW. Topological defects induce layer formation in Myxococcusxanthus colonies. arXivorg 2020. arXiv:2001.03804
171. Giniunaite R, McLennan R, McKinney MC, Baker RE, Kulesa PM, Maini PK An interdisciplinary approach to investigate collective cell migration in neural crest. Dev Dyn. 2020:249:270-80.

172. McLennan R, McKinney MC, Teddy JM, Morrison JA, Kasemeier-Kulesa JC, Ridenour DA, Manthe CA, Giniunaite R, Robinson M, Baker RE, et al. Neural crest cells bulldoze through the microenvironment using Aquaporin 1 to stabilize filopodia. Development. 2020. https://doi. org/10.1242/dev.185231.

173. Christley S, Alber MS, Newman SA. Patterns of mesenchymal condensation in a multiscale, discrete stochastic model. PLoS Comput Biol. 2007;3:e76.0743-0753.

174. True JR, Haag ES. Developmental system drift and flexibility in evolutionary trajectories. Evol Dev. 2001;3:109-19.

175. Newman SA. Inherency and homomorphy in the evolution of development. Curr Opin Genet Dev. 2019;57:1-8.

176. Bonner JT. The evolution of evolution: seen through the eyes of a slime mold. Bioscience. 2015;65:1184-7.

177. Travisano M, Velicer GJ. Strategies of microbial cheater control. Trends Microbiol. 2004;12:72-8

178. Folse HJ 3rd, Roughgarden J. What is an individual organism? A multilevel selection perspective. Q Rev Biol. 2010;85:447-72.

179. Gómez-Santos N, Glatter T, Koebnik R, Swiatek-Polatynska MA, SogaardAndersen L. A TonB-dependent transporter is required for secretion of protease PopC across the bacterial outer membrane. Nat Commun. 2019;10:1360.

180. Szadkowski D, Harms A, Carreira LAM, Wigbers M, Potapova A, Wuichet K, Keilberg D, Gerland U, Sogaard-Andersen L. Spatial control of the GTPase MglA by localized RomR-RomX GEF and MglB GAP activities enables Myxococcus xanthus motility. Nat Microbiol. 2019:4:1344-55.

181. York JR, McCauley DW. The origin and evolution of vertebrate neural crest cells. Open Biol. 2020;10:190285.

182. Pigliucci M, Müller G, editors. Evolution, the extended synthesis. Cambridge: MIT Press; 2010.

183. Abouheif E, Wray GA. Evolution of the gene network underlying wing polyphenism in ants. Science. 2002;297:249-52.

184. Müller GB, Newman SA. The innovation triad: an EvoDevo agenda. J Exp Zool B Mol Dev Evol. 2005;304:487-503.

185. Müller GB. Homology: the evolution of morphological organization. In: Müller GB, Newman SA, editors. Origination of organismal form: beyond the gene in developmental and evolutionary biology. Cambridge: MIT Press; 2003. p. 51-69.

186. Müller GB. Why an extended evolutionary synthesis is necessary. Interface Focus. 2017;7:20170015.

187. Vavilov NI. The law of homologous series in variation. J Genet. 1922;12:47-89.

188. Sebé-Pedrós A, Irimia M, Del Campo J, Parra-Acero H, Russ C, Nusbaum C, Blencowe BJ, Ruiz-Trillo I. Regulated aggregative multicellularity in a close unicellular relative of metazoa. Elife. 2013;2:e01287.

189. Newman SA. Animal egg as evolutionary innovation: a solution to the "embryonic hourglass" puzzle. J Exp Zool B Mol Dev Evol. 2011:316:467-83.

190. Tikhonenkov DV, Hehenberger E, Esaulov AS, Belyakova OI, Mazei YA, Mylnikov AP, Keeling PJ. Insights into the origin of metazoan multicellularity from predatory unicellular relatives of animals. BMC Biol. 2020;18:39.

191. Camley BA, Rappel WJ. Physical models of collective cell motility: from cell to tissue. J Phys D Appl Phys. 2017;50:113002.

\section{Publisher's Note}

Springer Nature remains neutral with regard to jurisdictional claims in published maps and institutional affiliations. 